\title{
Functional diversity responses to changing species richness in reef fish communities
}

\author{
Benjamin S. Halpern ${ }^{1, *}$, Sergio R. Floeter ${ }^{1,2}$ \\ ${ }^{1}$ National Center for Ecological Analysis and Synthesis, 735 State Street, Santa Barbara, California 93101, USA \\ ${ }^{2}$ Depto. de Ecologia e Zoologia - CCB, Universidade Federal de Santa Catarina, Flórianopolis, Santa Catarina 88010-970, Brazil
}

\begin{abstract}
Functional diversity in biological communities is critical for providing the full suite of ecosystem functions and services, yet the relationship between functional diversity and species richness - how diversity is usually measured - remains largely unknown. Here we evaluate empirically how different measures of functional diversity change with increasing species richness across 36 Atlantic reef fish communities that vary greatly in species richness. We show that (1) the definition used for functional groups strongly influences the perceived relationship; (2) when using more comprehensive definitions of functional groups the relationship is asymptotic and highly unsaturated; and (3) increasing species richness primarily leads to the addition of species to a few key functional groups rather than the addition of novel functional groups. Consequently, non-random assembly of fish assemblages leaves many possible functional groups empty, and high species redundancy within functional groups is limited to relatively few groups. Consequences of future extirpation or extinction of species for the loss of ecosystem functions will be variable, in part depending on the proportion of species lost within a functional group, but potentially profound due to the large number of functional groups represented by only a single species and the targeted nature of most species extraction and extirpations.
\end{abstract}

KEY WORDS: Biodiversity $\cdot$ Ecological filtering $\cdot$ Community assembly $\cdot$ Species loss $\cdot$ Ecosystem services

\section{INTRODUCTION}

Humans derive a vast number of services from biological communities, and these services emerge from the ecosystem functions provided by the species within the communities (Naeem et al. 1994, Loreau et al. 2001). Every species may provide a unique function to an ecosystem, yet clearly many species can have very similar functional roles. For example, species can be grouped by their trophic position, their ability to fix nitrogen, or their provision of resources (e.g. habitat), and these functional groupings provide insight into the assembly, structure and dynamics of ecological communities (Hairston et al. 1960, Tilman et al. 1997, Mayfield et al. 2005). Depending on the degree of overlap (redundancy) in species' functional roles, the addition or loss of a few species will have profound to minimal impacts on ecosystem function. To help distinguish among the possible ecosystem consequences of changing species richness we need to understand how species richness affects functional diversity. Surprisingly little is known about this relationship in natural, complex systems (Naeem 2002, Hooper et al. 2005, Micheli \& Halpern 2005).

Importantly, the shape of the relationship between these 2 types of diversity is known for very few communities (Naeem 2002), and has never been tested for species-rich ( $>100$ species) communities. This shape can provide insight into how communities assemble over evolutionary time scales (i.e. whether new species add new functional groups or increase the redundancy within existing groups), and the potential ecological consequences of species extirpation or extinction, and patterns of functional group composition can be used to evaluate the causes, or potential mechanisms, and consequences of species redundancy (or lack thereof). For 
example, a linear relationship between species and functional diversity would suggest low overall redundancy within functional groups and therefore greater potential consequences of human activities that remove or add species to a community (Micheli \& Halpern 2005), while uneven distribution of species within functional groups can help illuminate mechanisms of community assembly or differential speciation among functional groups (e.g. Kotrschal 1988, Ferry-Graham et al. 2002).

Theoretical work suggests that increases in species richness should lead to positive, nonlinear and asymptotic increases in functional diversity (Fonseca \& Ganade 2001, Petchey \& Gaston 2002a,b). However, the shape of this relationship depends in part on the number of species measured and functional groups defined in the system. With relatively few species, every species is likely to be assigned a unique functional group, creating a linear relationship, in particular when there are many functional groups defined (species:functional groups $<1$; Fig. 1). In contrast, many species with few functional groups will fill all functional groups even at relatively low species richness, creating an artifact ('ceiling') in the perceived relationship simply because one has constrained the number of functional groups to a small subset of possible ecosystem functions. Between these 2 extremes, where the ratio of species to functional groups is greater than one but less than perhaps 10, an asymptotic relationship is expected. Empirical tests of the theory have produced conflicting outcomes, both con-

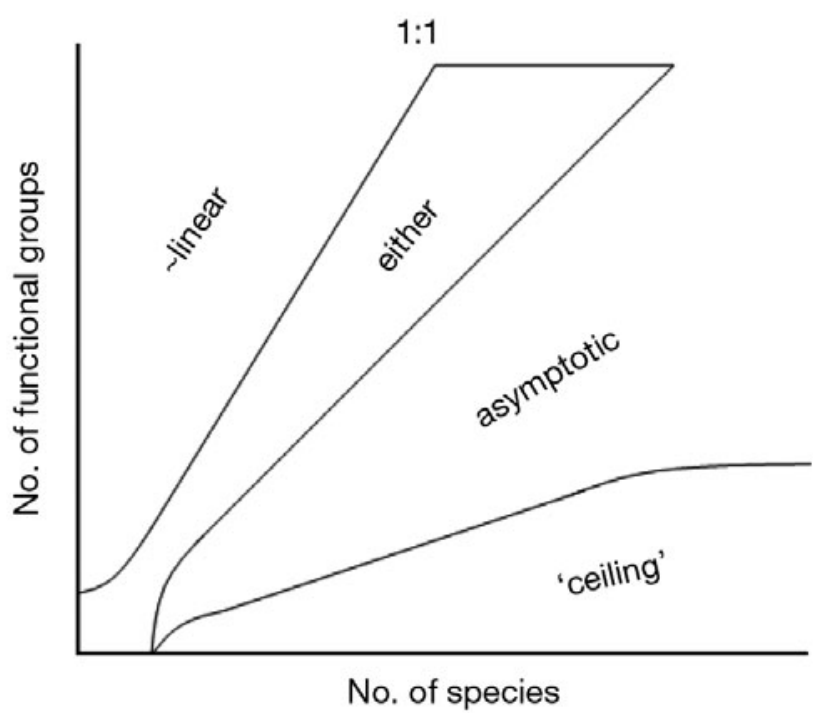

Fig. 1. Predicted shape of the relationship between species richness and functional group richness across different levels of richness. The 1:1 line indicates where species and functional group richness are roughly equal. Where few species exist, it can be difficult to distinguish between potential curves firming (Stevens et al. 2003, Mayfield et al. 2005) and contradicting (Micheli \& Halpern 2005) the theoretical predictions. However, all of these empirical studies have focused on communities with relatively few species, often with very few functional groups in a single trophic level. In other words, our current picture of the nature of the species-functional group relationship has come from systems with relatively few species, which constrains the likely type of relationship that could be found. We examine here this relationship in natural, species-rich (>100 species) communities.

\section{MATERIALS AND METHODS}

Reef fish database. Species lists were developed for 36 locations around the Atlantic Ocean (Fig. 2) through literature searches of peer-reviewed reports of species distributions, from published field guides, and from extensive personal observation and exhaustive sampling (including rotenone stations by Smith-Vaniz et al. 2006; see Floeter et al. 2008), and for site details, see Table A1 (available at: www.int-res/articles/suppl/ m364p147_app.pdf). Locations were included only if data were available for entire reef fish communities and are therefore haphazardly distributed across the Atlantic. These data represent the most exhaustive species richness data for Atlantic reef fish communities and include cryptic, rare and endemic species as well as the common and abundant ones (Floeter et al. 2008).

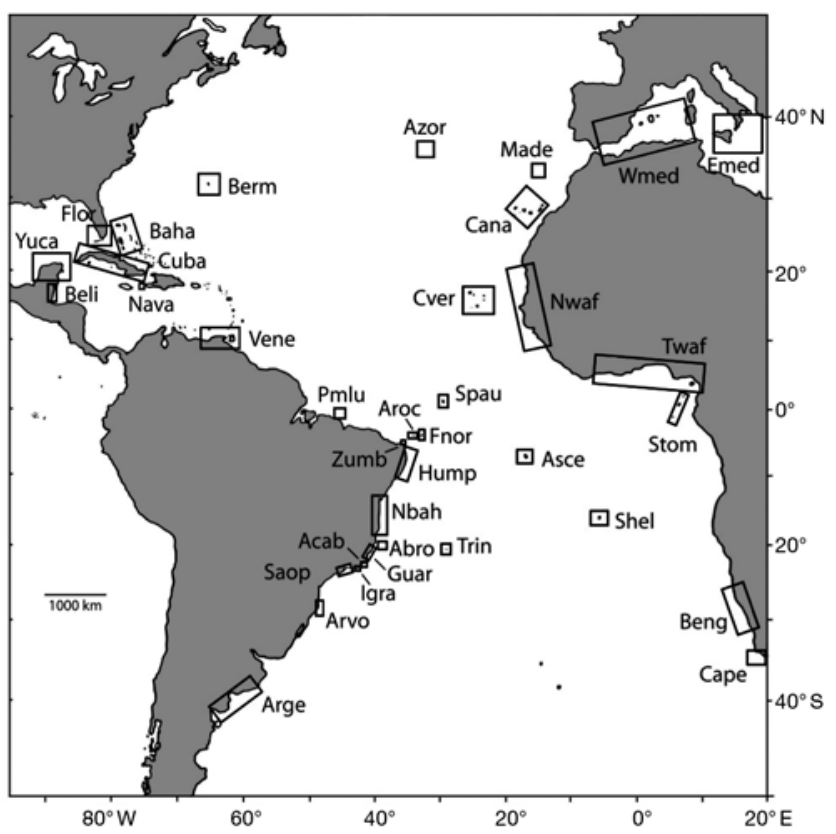

Fig. 2. Atlantic reef fish community sites. The map shows locations where species-presence data were collected. See Table A1 (www.int-res/articles/suppl/m364p147_app.pdf) for site names and characteristics 
Although sampling effort was not equal at all locations, a sampling bias is unlikely as our patterns of species richness match those for other taxa such as corals (Veron 1995) and muricid gastropods (Vermeij 1996), and several of the least studied locations (e.g. Western Africa) have some of the highest species richness (Table A1). In total, 1623 species from 465 genera and 69 families were recorded (Table A2).

Importantly, we were not trying to explain what causes the differences in assemblage-wide species richness, so we did not measure or account for the many factors that can affect the structure of fish assemblages, which are likely to vary greatly among the 36 locations used in these analyses, including biogeographic constraints. However, 3 location variables could affect the number of species within functional groups. First, latitudinal gradients are known to affect groups of marine species differently (e.g. Harmelin-Vivien 2002, Floeter et al. 2004,2005); indeed, the relationship between mean sea surface temperature (SST) at a location (methods described in Floeter et al. 2005) and overall species richness was marginally significant, although with poor explanatory power (linear regression, $F=$ 4.20 , df $=34, \mathrm{p}=0.05, \mathrm{R}^{2}=0.11$ ). To further explore this potential relationship, we used linear regression analysis to test whether species richness within each trophic functional group was related to SST. Second, biogeographic constraints could affect species radiations within functional groups. In our study, biogeographic regions are strongly related to species richness (Table A1). To address these potential constraints, we used linear regression to evaluate how the number of species within each functional group changed relative to changing species richness. Third, the scale of each location was determined by the scale of the published records, and so differs among locations. Larger sampling areas or sites might be more likely to capture rare species in potentially unique functional groups. The scale of locations did not differ systematically by latitude or estimated species richness (the largest locations are distributed over all regions of the Atlantic and encompass the full range of possible species richness values), such that location size should not bias results. However, to test for potential biases, we conducted key analyses without those locations that were disproportionately larger than others. We found no differences in results (see Fig. A1), and so we report results for all locations here. Furthermore, we limited our analyses to reef fishes (living in coral or rocky reefs) such that increasing location size would not necessarily increase habitat (and associated species) richness. In other words, our focus on a single habitat type minimizes the potential effect of location size on species richness and ensures that species have the potential to interact (i.e. they are a single community).
Functional group classifications. A variety of techniques have been developed to classify species into functional groups based on either ecosystem functions, such as productivity or nutrient cycling (Tilman et al. 1997, Hector et al. 1999), or on community function such as trophic level (Mayfield et al. 2005, Micheli \& Halpern 2005) (reviewed in Petchey \& Gaston 2006). We focus here on community functional traits, primarily because the dominant ecosystem function for most species of fish is not known and the community approach is commonly used for fishes. Ideally, functional groups would be defined post-hoc using experimental manipulations to define the true functional role of each species (Wright et al. 2006). However, such techniques are not realistically possible for entire reef fish communities, so we rely on the common a priori method (Wright et al. 2006) while noting that all methods have inherent limitations (Naeem \& Wright 2003, Petchey \& Gaston 2006, Wright et al. 2006).

We used a variety of different community function classification schemes to assign each reef fish species to a functional group. Using different methods provides a test of the sensitivity of results concerning how species are assigned to functional groups. We first used 3 single-variable methods, with species assigned to functional groups based on trophic group, maximum body size, or maximum depth. Standard trophic classifications gave 14 different groups (see Table A2 for classifications) based on Bellwood et al. (2004) and Ferreira et al. (2004). Maximum body size dictates predator-prey interactions via gape, body dimensions, gut length, and other morphological traits that affect feeding behavior, size and type of food that can be consumed (Scharf et al. 2000, Jennings et al. 2002, Kulbicki et al. 2005); classification of species using this method gave 4 maximum size categories $(<10$, $10-25,25-50$, and $>50 \mathrm{~cm}$ ). Finally, classification by maximum depth, which is related to the spatial separation of access to food resources (Thresher \& Colin 1986, Nagelkerken et al. 2001, Fox \& Bellwood 2007), gave 5 maximum depth categories (very shallow: $<10 \mathrm{~m}$, shallow: 10-25 m, medium: 25-50 m, deep: 50-100 m; very deep: >100 m) (Liddell \& Ohlhorst 1987, McGehee 1994). The latter 2 variables are proxy measures of actual community (trophic) function, but can help differentiate between species with similar trophic classification, but that consume different resources because of ability (e.g. gape size, swimming speed) or access (i.e. depth strata).

Maximum length and depth values were obtained from a number of primary sources (see Table A3). We assigned the average value for the genus (or family if there were no congeners) when maximum length or depth for a species could not be found (21.6 and $27.8 \%$, respectively). In relatively few of these cases 
did the range of values for a genus or family span more than a single length category (6.6\% of all species), although there were more cases for depth categories (17.8\% of all species). Misidentification of functional groups for species within genera that fall within a single depth and size category should be minimized by using this method, assuming phylogenetic constraints (i.e. species are more likely to be similar to their congeners). However, to test the potential influence of assigning average genera values to species with unknown values on our results, we removed these species and re-evaluated all relationships. Results were qualitatively identical (see Fig. A2), so we focus on the results derived from including all species.

We also assigned fish to groups based on different combinations of 2 functional traits and all 3 traits (providing a total of 7 different methods for describing functional groups, with varying numbers of maximum possible groups). Not all combinations occur in nature, resulting in 70 (of 70), 50 (of 56), 20 (of 20), and 256 (of 280) realistic combinations for the trophic-depth, trophic-size, depth-size, and trophic-depth-size groupings, respectively. Functional groups that do not occur in nature include $<10 \mathrm{~cm}$ macrocarnivores, $>50 \mathrm{~cm}$ spongivores, $25-50$ and $>50 \mathrm{~cm}$ territorial herbivores, $>50 \mathrm{~cm}$ turf herbivores, and $<10 \mathrm{~cm}$ excavators.

We recognize that many species may not fit easily into a particular functional group because of temporal, spatial or ontogenetic shifts in diet, or simply because of a lack of full diet information. Furthermore, the traits we use to classify species into functional groups are not fully independent, such that certain combinations are likely to be more common. For example, large-bodied fish are rarely restricted to very shallow depths and macro-carnivores will tend to be larger. We directly address this issue by using multiple approaches to defining functional groups; if similar results arise from these different classification schemes, then any potential bias in the results due to misclassification of species into functional groups is likely to be minimal. We further tested the sensitivity of our results concerning how species were classified by using an alternate, coarser system of 7 trophic groups: diurnal planktivores, herbivores (excavators, macro-algal eaters, scrapers, territorial herbivores, and turf algal eaters), macrocarnivores (macrocarnivores and piscivores), macro-invertebrate eaters (macro-invertebrate eaters and sand invertivores), nocturnal planktivores, omnivores (omnivores and spongivores), and sessile invertebrate eaters (see Fig. A2). Results were qualitatively identical, so we report here only the main results.

Measures of functional diversity. We used $3 \mathrm{com}-$ mon metrics of functional diversity when comparing species to functional group diversity: richness (i.e. the number of species within a community, S), evenness, and Shannon's H diversity (Mason et al. 2005). Shannon's $H$ is calculated as

$$
H=\sum_{i=1}^{S} p_{i} \ln p_{i}
$$

where $S$ is the number of species in the community, and $p_{i}$ is the proportion of $\mathrm{S}$ of the $i$ th species. Evenness is calculated as the ratio

$$
H /(\log S)
$$

Each diversity measure provides unique information about how functional group diversity responds to changes in species richness, including the loss or addition of unique functional groups (richness), the number of species per functional group that are present (diversity), and the skew in the distribution of the number of species per functional group (evenness).

Null model. To develop a null model for expected relationships between species richness and the 3 measures of functional group diversity, we focused on the definition of functional group based on the combination of trophic, size and depth variables. We simulated communities by randomly drawing functional groups from the full list of naturally occurring groups $(\mathrm{N}=$ 256), with replacement, for as many times as there are species in each of the Atlantic communities (54 to 474 species). This approach evaluates how hypothetical species fill possible functional groups. The alternate null model, where species are selected without replacement, was not used, as it either inappropriately draws species from the entire Atlantic species pool (if all 1623 species were used) or constrains communities to only those species that currently exist at a particular location, rather than allowing for all species that occur in nature. Simulated communities were created 10000 times for each species richness level, and the average values for the 3 measures of functional group diversity were calculated.

Statistical analyses. Linear regression analysis was used to evaluate the change in species richness in each of the 256 functional groups with increasing community-wide species richness. Nonlinear fits were also tested but had equal or lower $\mathrm{R}^{2}$ values in nearly all cases, so we only report statistics for linear fits.

\section{RESULTS}

When diet, size, or depth alone was used to define functional groups, the relationship between species and functional group richness hit a 'ceiling' of possible values (Fig. 3A-C). For example, when functional groups were defined by organism size, all levels of species richness included all 4 size groups (Fig. 3A), giving a methodological (i.e. artificial) rather than eco- 

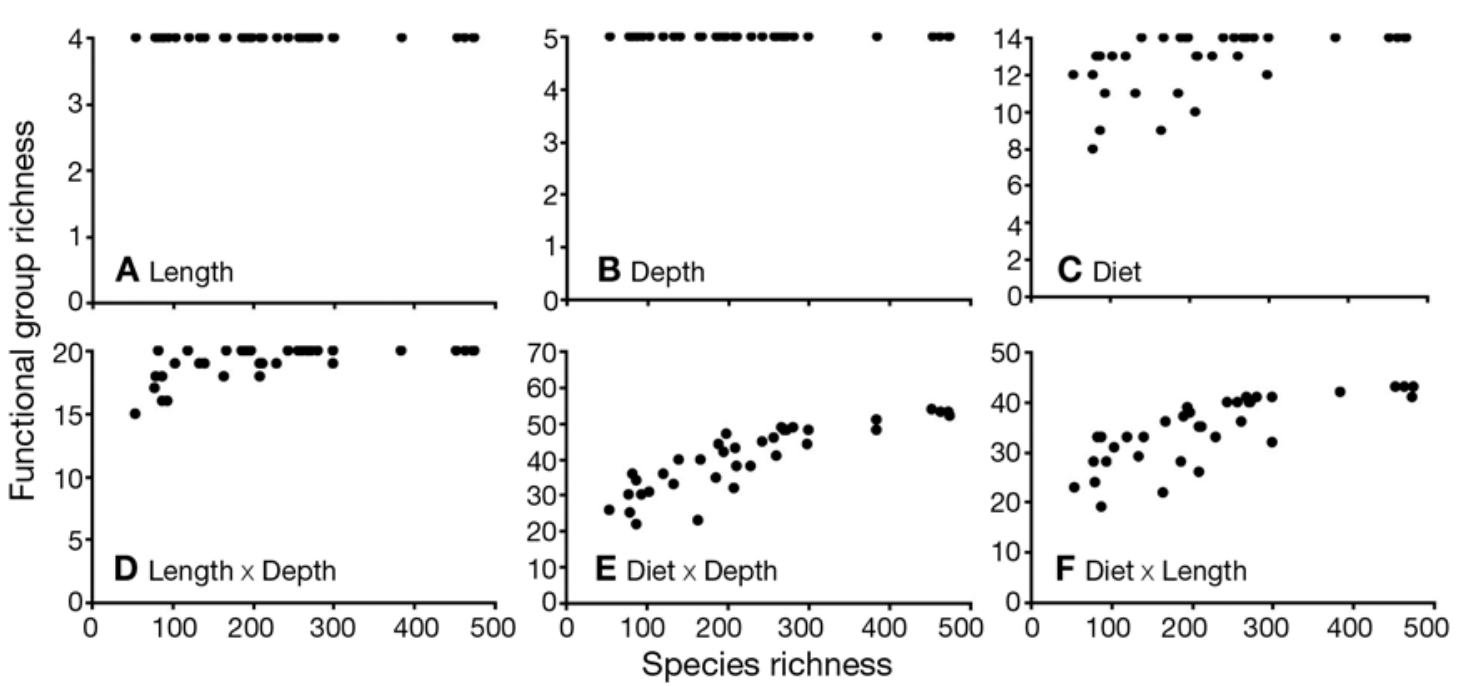

Fig. 3. Species versus functional group richness for 6 different functional group classification schemes. Functional group richness axes are scaled to the maximum possible number of functional groups, based on the definition used for that plot. A ceiling effect is clear in (A-D), where the total number of possible functional groups is small, but is absent in (E,F), where maximum possible functional group richness is 70 and 50 , respectively

logical result of a linear and flat relationship between species and functional group richness. When this ceiling effect was removed by classifying species into a greater number of functional groups (that are still ecologically meaningful and distinct), a clear non-linear (asymptotic) relationship emerged between species and functional group richness (Fig. 3E,F), except when combinations of functional traits produced too few functional groups to overcome the ceiling effect (Fig. 3D). The non-linear relationship persisted when functional groups were classified by combinations of the 3 functional traits, and the relationship approached an asymptote at a level significantly lower (unsaturated) than expected by random chance (Fig. 4A). These results hold for Shannon functional diversity (Fig. 4B), in part because evenness declined as species richness increased (new species were added to existing species-rich functional groups, rather than to new or species-poor functional groups; Fig. 4C).

When using the functional groups based on all 3 variables, 39 of the 256 possible functional groups $(15.2 \%)$ have only a single species at any given location (Table A4), although groups that differ only in their maximum depth category may coexist at shallower depths. Several of these species play critical ecological roles in reef communities, such as the large macroalgal eater Sarpa salpa, the mid-size spongivore Holacanthus africanus, the large sessile inverterbrate eater Diodon hystrix, and Scarus hoefleri, S. trispinosus, and Sparisoma viride in the large scraper herbivore and the excavator/eroder functional groups (e.g. Bellwood et al. 2003, Ferreira \& Goncalves 2006). Equally striking is the order in which functional groups were added or enriched with increasing species richness. A variety of predators of all sizes at all depths (macrocarnivores, piscivores, sessile invertebrate eaters, sandy-bottom invertebrate eaters, and diurnal and nocturnal planktivores) were not present in species-poor communities (<100 sp.), but were present in species-rich communities (Fig. 5A-C; Table A4). Similarly, although 105 of the naturally occurring 256 functional groups showed statistically significant increases in the number of species per group with increasing species richness, most of these numerical increases occurred in predator functional groups (macrocarnivores, mobile benthic-invertebrate eaters, piscivores, sessile invertebrate-eaters, sandybottom invertebrate eaters, and diurnal planktivores, of all sizes at all depths; Fig. 5D-F, Table A4). Seven of the 10 most significant increases (highest $\mathrm{R}^{2}$ values and large numerical increases) were mobile benthicinvertebrate eaters (Table A4). In particular, in the 5 most species-rich communities, 3 functional groups alone accounted for 133 (28\%) additional species (0-10 cm mobile benthic-invertebrate eaters at $0-10$, 10-25, and 25-50 m depths; primarily from the families Gobiidae and Chaenopsidae). In contrast, entire suites of excavators, macroalgal eaters, nocturnal planktivores, and spongivores (from a variety of sizes and depths) were absent from all communities, even the most species-rich ones (Table A4).

Trophic functional groups had differential relationships with average SST at a location. Of the 14 groups, 6 showed no relationship (macroalgal eaters, macrocarnivores, omnivores, and mobile benthic, sandybottom, and sessile-invertebrate eaters), with sandy- 

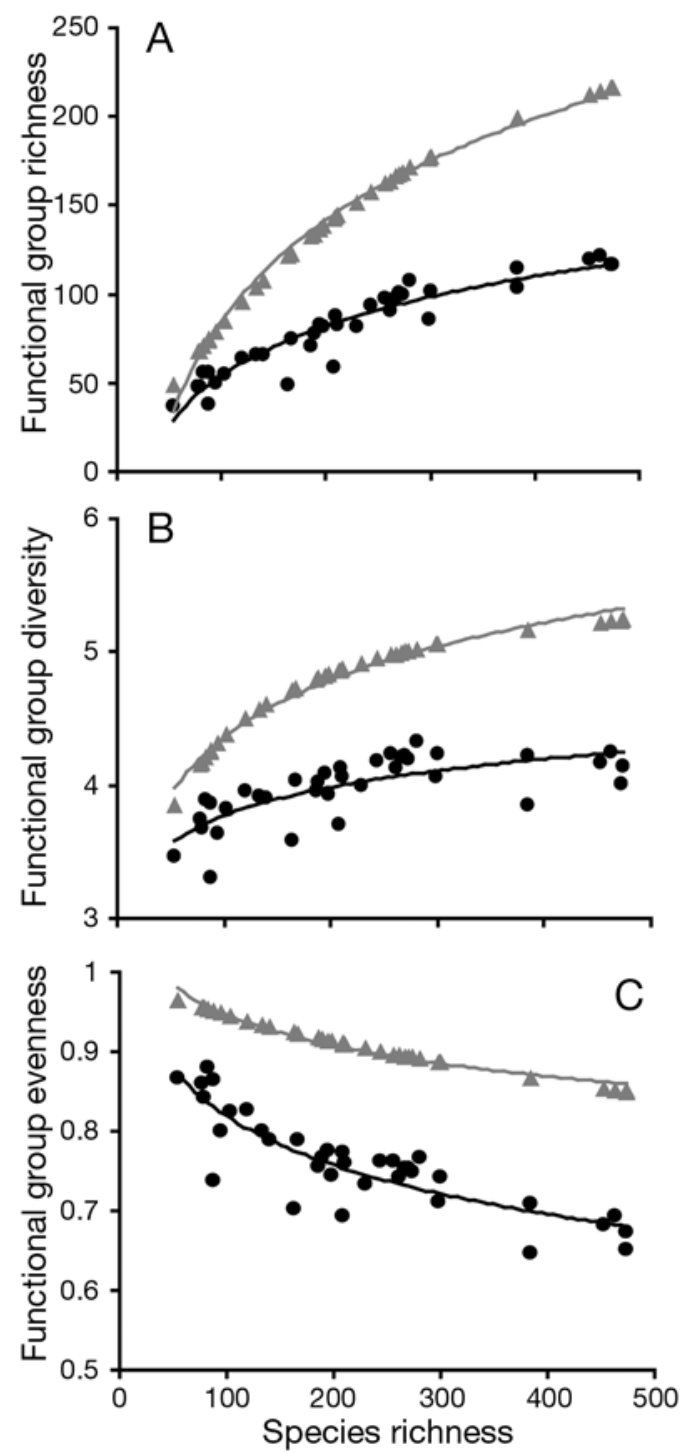

Fig. 4. Species richness versus 3 measures of functional group diversity. Functional groups are defined by the combination of diet, size and depth (see 'Materials and methods'). Null model results are gray triangles; data from Atlantic reef fish communities are black circles. Regression lines are logarithmic best-fits. Real data show a non-linear relationship that is significantly lower than null expectations

bottom invertebrate eaters actually showing a negative but not significant trend with increasing SST. Five other groups (diurnal and nocturnal planktivores, excavators, piscivores, and scrapers) showed significant increases in species richness with increasing SST, but with relatively poor fit $\left(\mathrm{R}^{2}<0.29\right.$ for all cases). The final 3 groups (spongivores, territorial algal eaters, and turf grazers) had highly significant relationships ( $\mathrm{p}<$ $0.0001)$ with high explanatory power $\left(R^{2}=0.38,0.54\right.$, and 0.55 , respectively).

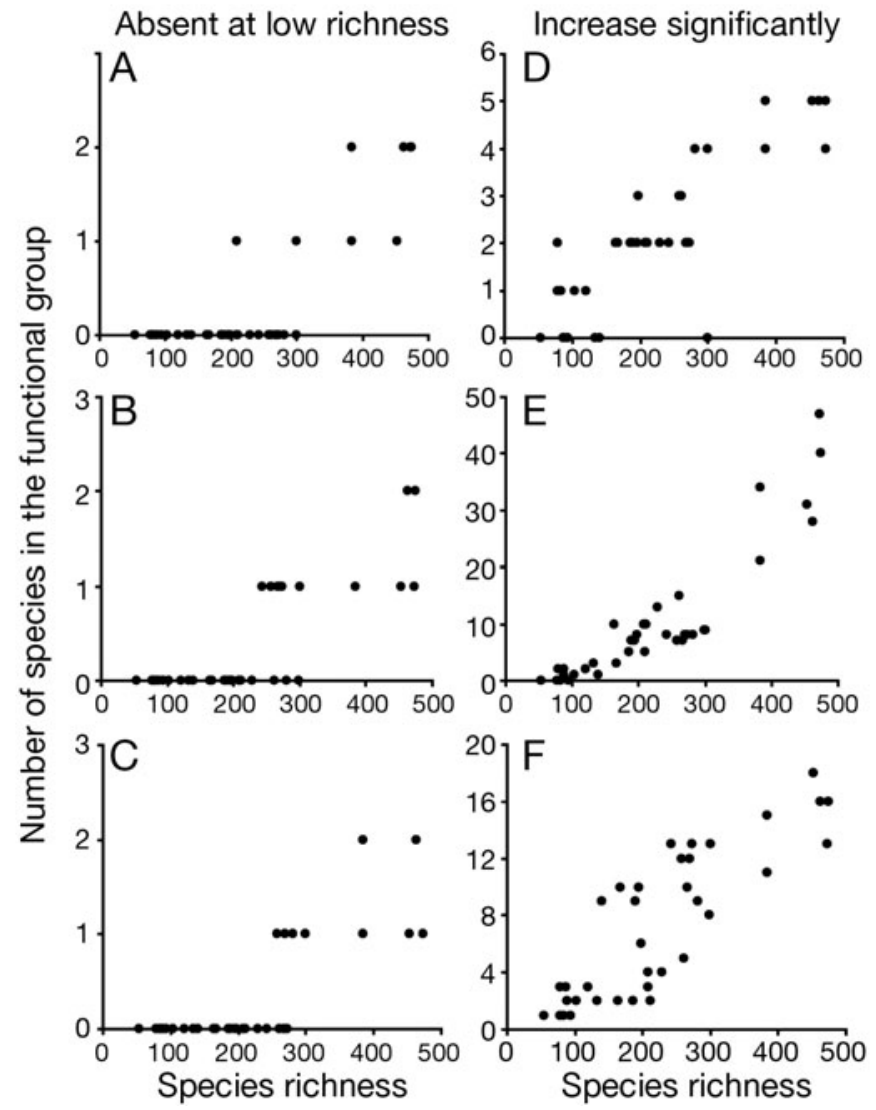

Fig. 5. Changes in the number of species in 6 functional groups with increasing community species richness. Plots are for representative functional groups that are not present when community species richness is low (A-C) and that significantly increase in richness as community species richness increases (D-F). Functional groups are (A) $10-25 \mathrm{~cm}$, medium-depth diurnal planktivores; (B) 10-25 cm, shallow macrocarnivores; (C) $>50 \mathrm{~cm}$, deep sandy-bottom invertebrate eaters; (D) 25-50 cm, medium-depth macrocarnivores; (E) $<10 \mathrm{~cm}$, shallow mobile benthic-invertebrate eaters; and

(F) 10-25 cm, deep mobile benthic-invertebrate eaters

\section{DISCUSSION}

Both theoretical and applied fields of research have been focusing for decades on biodiversity and its role in driving ecological and evolutionary processes and providing ecosystem services. However, in most cases the functional roles or identities of species, not simply the number of species, affect ecosystem functions and services. In this study, we evaluated the relationship between species and functional diversity in natural, species-rich communities to identify the shape of the relationship and its potential causes and consequences, and found several results. First, the expected relationship between species and functional diversity depends on the relative proportion of functional groups to species, as well as the total number of spe- 
cies, since an asymptotic relationship may appear linear at low levels of species richness (Fig. 1). Furthermore, the ceiling effect we demonstrated is non-trivial if studies are trying to infer, beyond the scope of a particular study, the general relationship between species and functional group diversity, as this ceiling constrains and influences the shape of the relationship between species richness and the 3 diversity measures. The shape would likely change in communities with fewer species or more functional groups. Indeed, the few empirical studies that have explored this relationship overlooked the consequences of the 'ceiling effect' when describing significantly non-linear relationships (Stevens et al. 2003, Mayfield et al. 2005). The only study unconstrained by this ceiling instead found linear relationships (Micheli \& Halpern 2005). However, the communities in this study contained $<100$ species and were likely in the initial, low-species richness, linear part of the asymptotic relationship we found here (Figs. $3 \& 4$ ). For studies only concerned with the relationship between species richness and a small subset of functional roles, a ceiling effect is meaningful rather than an artifact, but otherwise spurious results are likely to arise when looking for species-functional group relationships in communities with relatively few species or in those for which the number of defined functional groups is too low.

Second, when this ceiling effect is removed, a clear asymptotic relationship emerges. This result confirms theoretical predictions (Fonseca \& Ganade 2001, Petchey \& Gaston 2002a,b), but is the first empirical test in species-rich communities spanning a wide range of richness. As the theoretical studies have pointed out, this asymptotic relationship indicates that adding new species to a speciose community tends to increase redundancy, rather than add new functional groups. We address below where this redundancy occurs and explore potential explanations.

Third, comparison of the reef fish communities to null model expectations showed highly unsaturated communities, with many functional groups absent (Fig. 4), suggesting that communities assemble in a non-random manner. These patterns could emerge from either evolutionary or ecological processes, with historical extinctions and limited dispersal into the Atlantic Ocean (Bellwood \& Wainwright 2002) setting the stage for future radiations or loss of taxa (i.e. evolutionary filtering: Webb et al. 2002, Vitt \& Pianka 2005), or from current ecological forces driving the success and distribution of species (i.e. ecological filtering). Others have found evidence for evolutionary filtering in the Atlantic, with larger or differential extinction rates for groups such as coral and mollusks, compared to the Indo-West Pacific (Jackson et al. 1993, Budd et al. 1996, Budd 2000). Unfortunately, the fossil record and phylogenies for most Atlantic reef fish are currently unknown (Bellwood \& Wainwright 2002), making robust tests of evolutionary drivers of species distributions and the resulting patterns in functional groups difficult at this time. However, biogeographic patterns and associated potential drivers of these patterns can shed some light on this question. For example, the dispersal modes (e.g. pelagic, demersal) of species in different functional groups may explain the patterns seen here - large predator species tend to have pelagic dispersal modes that facilitate connection among locations (e.g. macro-carnivores are 100\% pelagic spawners), while mid-trophic groups more commonly have demersal spawning that restricts dispersal (e.g. approximately half of the herbivores are demersal spawners) (Vermeij 2004). Indeed, the high diversity of some small-bodied, demersal-spawning families like Labrisomidae and Gobiidae - most of them mobileinvertebrate eaters (i.e. microcarnivores) - across the Atlantic has been suggested to result from short dispersal, leading to limited gene flow and high rates of speciation (Munday \& Jones 1998, Taylor \& Hellberg 2005). However, nocturnal planktivores provide an example to the contrary, as these have a much larger proportion of demersal spawners but only 29 species throughout the entire Atlantic, suggesting that explanations or causes are likely multi-factorial.

Furthermore, the relative absence of mid-trophic levels and the strong skew in the number of species within functional groups, where some groups had only single species while others had tens of species, provide support for differential ecological filtering among locations. Such patterns could result from processes such as single-species dominance of a functional group, greater defenses to consumption in basal-trophic species (algae, sponges) compared to mid-level species, physiological constraints for herbivorous fishes (Floeter et al. 2005), morphometric limitations (such as gape size) that constrain possible functional groups, or regional differences in resource availability (e.g. corals are primarily found in tropical latitudes). The actual reasons why such filtering would disproportionately affect mid-trophic groups of Atlantic reef fishes remains poorly understood and merits further research.

The highly uneven distribution of species within functional groups is particularly striking. Some functional groups consistently have more species, regardless of location, and these groups (both macro- and micro-predators) add the most species as communities become more species rich. We also found that some functional groups, particularly the sponge-, coral-, and algal-eaters, were more speciose in warmer locations, supporting potential biogeographic drivers for these results. However, these functional groups had relatively few species, so that these patterns had little 
effect on overall community species richness. A possible interpretation of these results is that not all functional groups are equal, and it may be easier to subdivide some groups (e.g. predators) while it is much more difficult to subdivide other groups (e.g. herbivores). Such a difference is perhaps not surprising, as predators can subdivide food niche space based on e.g. the behavior, habitat preference, size, or feeding strategies of their prey; they have high quality (high protein) diets that may allow for greater species radiations since they are less energetically constrained (e.g. Floeter et al. 2004); and they encounter fewer chemical defenses in their prey or physiological constraints in prey consumption (Harmelin-Vivien 2002, Floeter et al. 2004). Alternatively, functional versatility among invertebrate feeders may be the key driver of their diversity (Bellwood et al. 2006). Versatility in resource use also permits repeated invasion of niche space by different lineages. For example, preliminary phylogenetic analyses (e.g. Westneat et al. 2005) suggest that the central region of labrid diet space (microcrustacea) has representatives from at least 6 different labrid lineages on the Great Barrier Reef alone. In contrast, mid-trophic levels, especially herbivores, spongivores, and coralivores, may face both physiological constraints in consumption (Floeter et al. 2005) and higher levels of chemical defenses in prey (Hay 1997), and potentially have fewer niche axes to use for niche subdivision (e.g. non-mobile prey have fewer behavioral options).

In a similar vein, we found that Atlantic reef fish diversity is concentrated in relatively few functional groups. These patterns are in part due to species radiations of gobies (Gobiidae) and tube blennies (Chaenopsidae) that have been suggested to arise from microhabitat and feeding specializations (Kotrschal \& Thomson 1986, Depczynski \& Bellwood 2004) and a variety of life-history traits that promote speciation, especially demersal spawning (Munday \& Jones 1998). However, similar radiations have not occurred in other functional groups with equivalent traits - the causes of these patterns remain poorly understood.

These differences in species richness among functional groups have particularly important consequences for understanding how human activities can affect biological communities and ecosystem functions in the future. The systematic depletion of species from many marine systems (Jackson et al. 2001, Dirzo \& Raven 2003, Myers \& Worm 2003) has rarely been random, and so future extirpations or extinctions of marine species are unlikely to follow the patterns of community assembly. When functional groups are nonindependent or have differential vulnerability to extinction (Pereira et al. 2004, Larsen et al. 2005), then key ecosystem functions may be lost rapidly with early species loss if remaining species are unable to adapt their functional role and fill these ecosystem functions. Indeed, the loss from communities of functional groups with single or a few, but abundant, species can have profound impacts on overall community structure and function (e.g. Bellwood et al. 2003, 2004), while the loss of other functional groups with single, but numerically rare, species may have relatively little consequence. Because there are relatively few anthropogenicinduced species extirpations or extinctions in Atlantic reef fish communities (Dulvy et al. 2003), the patterns of species and functional diversity we found are not yet a result of human impact and instead provide a map of the potential consequences of continued threats to the fish communities at these locations. The higher diversity of predator functional groups may have provided an initial buffer for ecosystem function against human impacts such as fishing, but as these activities shift to lower-diversity mid-trophic levels, the consequences to ecosystem functioning may become more pronounced. Being able to recognize and predict which functional groups play dominant roles in controlling overall ecosystem functions will be critical for refining our understanding of how species loss affects ecosystem function.

Our approach here explicitly focuses on species richness, rather than diversity. Differences in the abundances of key species may in part explain why some functional groups have many species while others have only a few - functional groups with many species may have lower abundances of each species, while functional groups with few species may have high abundance of these species. However, a variety of abundance patterns exist in Atlantic reef fish, such that these differences alone cannot explain the relationship between species and functional group diversity that we found. For example, herbivores are abundant in the tropics with relatively few species per functional group, while mobile invertebrate feeders are speciesrich and abundant everywhere (Ferreira et al. 2004, Floeter et al. 2004). Furthermore, good abundance data for every species in a community are rare, and so most studies of species-functional group relationships have had to rely on richness measures. Our focus here was on understanding the species-functional group relationship, given the current approaches to research and constraints in data availability. Our approach was also limited by being observational rather than experimental. However, it is powerful in that it can be quickly applied to many other taxa in a variety of ecosystems to help explore if, how, and why the relationship between species richness and functional diversity might vary geographically and taxonomically.

As human populations continue to grow around the world and demand for resources increases, local to 
global extinctions and introductions of species will continue to occur. We have shown here that species losses from natural, species-rich communities may have significant consequences for functional diversity and the ecosystem services that derive from these functions, because so many functional groups have few to only one species. This problem is exacerbated by the targeted nature of species extraction by humans. For example, a single species of roving herbivore (excavator) in the Pacific (Bolbometopon muricatum) has been shown to be responsible for most of the bioerosion of coral reefs in the Indo-West Pacific, and fishing pressure on this species has fundamentally changed reef accretion dynamics (Bellwood et al. 2003). In contrast, restoration and conservation efforts may be able to produce rapid recovery of ecosystem functions with the addition of only a few species, but the exact consequences will depend as much, if not more, on the numeric abundance of key species and functional groups and the presence of ecosystemspecific thresholds, rather than the richness of these groups.

Acknowledgements. Thanks to the many people who provided their data and unpublished manuscripts on species distributions and to C. Kappel, R. Stevens, J. Madin, M. Paddack, C. Ferreira, and several anonymous reviewers for helpful comments on earlier drafts of this paper and for help with classifying species into functional groups. Support was provided by the US National Center for Ecological Analysis and Synthesis (B.S.H., S.R.F.), the David and Lucille Packard Foundation (B.S.H.), and the National Geographic Society (S.R.F.).

\section{LITERATURE CITED}

Bellwood DR, Wainwright PC (2002) The history and biogeography of fishes on coral reefs. In: Sale PF (ed) Coral reef fishes: dynamics and diversity in a complex ecosystem. Academic Press, San Diego, CA, p 5-32

Bellwood DR, Hoey AS, Choat JH (2003) Limited functional redundancy in high diversity systems: resilience and ecosystem function on coral reefs. Ecol Lett 6:281-285

Bellwood DR, Hughes TP, Folke C, Nystrom M (2004) Confronting the coral reef crisis. Nature 429:827-833

Bellwood DR, Wainwright PC, Fulton CJ, Hoey AS (2006) Functional versatility supports coral reef biodiversity. Proc R Soc Lond B Biol Sci 273:101-107

Budd AF (2000) Diversity and extinction in the Cenozoic history of Caribbean reefs. Coral Reefs 19:25-35

Budd AF, Johnson KG, Stemann TA (1996) Plio-Pleistocene turnover and extinctions in the Caribbean reef coral fauna. In: Jackson JBC, Budd AF, Coates AG (eds) Evolution and environment in tropical America. University of Chicago Press, Chicago, IL, p 168-204

> Depczynski M, Bellwood DR (2004) Microhabitat utilisation patterns in cryptobenthic coral reef fish communities. Mar Biol 145:455-463

Dirzo R, Raven PH (2003) Global state of biodiversity and loss. Annu Rev Environ Resour 28:137-167

Dulvy NK, Sadovy Y, Reynolds JD (2003) Extinction vulnerability in marine populations. Fish Fish 4:25-64

Ferreira CEL, Goncalves JEA (2006) Community structure and diet of roving herbivorous reef fishes in the Abrolhos Archipelago, south-western Atlantic. J Fish Biol 69: 1533-1551

Ferreira CEL, Floeter SR, Gasparini JL, Ferreira BP, Joyeux JC (2004) Trophic structure patterns of Brazilian reef fishes: a latitudinal comparison. J Biogeogr 31:1093-1106

- Ferry-Graham LA, Bolnick DI, Wainwright PC (2002) Using functional morphology to examine the ecology and evolution of specialization. Integr Comp Biol 42:265-277

Floeter SR, Ferreira CEL, Dominici-Arosemena A, Zalmon IR (2004) Latitudinal gradients in Atlantic reef fish communities: trophic structure and spatial use patterns. J Fish Biol 64:1680-1699

> Floeter SR, Behrens MD, Ferreira CEL, Paddack MJ, Horn $\mathrm{MH}$ (2005) Geographical gradients of marine herbivorous fishes: patterns and processes. Mar Biol 147:1435-1447

Floeter SR, Rocha LA, Robertson DR, Joyeux JC and others (2008) Atlantic reef fish biogeography and evolution. J Biogeogr 35:22-47

Fonseca CR, Ganade G (2001) Species functional redundancy, random extinctions and the stability of ecosystems. J Ecol 89:118-125

> Fox RJ, Bellwood DR (2007) Quantifying herbivory across a coral reef depth gradient. Mar Ecol Prog Ser 339:49-59

$>$ Hairston NG, Smith FE, Slobodkin LB (1960) Community structure, population control, and competition. Am Nat 94: $421-425$

Harmelin-Vivien ML (2002) Energetics and fish diversity on coral reefs. In: Sale PF (ed) Coral reef fishes: dynamics and diversity in a complex ecosystem. Academic Press, San Diego, CA, p 265-274

> Hay ME (1997) The ecology and evolution of seaweed-herbivore interactions on coral reefs. Coral Reefs 16:S67-S76

> Hector A, Schmid B, Beierkuhnlein C, Caldeira MC and others (1999) Plant diversity and productivity experiments in European grasslands. Science 286:1123-1127

> Hooper DU, Chapin FS, Ewel JJ, Hector A and others (2005) Effects of biodiversity on ecosystem functioning: a consensus of current knowledge. Ecol Monogr 75:3-35

Jackson JBC, Jung P, Coates AG, Collins LS (1993) Diversity and extinction of tropical American mollusks and emergence of the isthmus of Panama. Science 260:1624-1626

Jackson JBC, Kirby MX, Berger WH, Bjorndal KA and others (2001) Historical overfishing and the recent collapse of coastal ecosystems. Science 293:629-638

Jennings S, Pinnegar JK, Polunin NVC, Warr KJ (2002) Linking size-based and trophic analyses of benthic community structure. Mar Ecol Prog Ser 226:77-85

Kotrschal K (1988) Evolutionary patterns in tropical marine reef fish feeding. Z Zool Syst Evolutionsforsch 26:51-64

Kotrschal K, Thomson DA (1986) Feeding patterns in eastern tropical Pacific blennioid fishes (Teleostei, Tripterygiidae, Labrisomidae, Chaenopsidae, Blenniidae). Oecologia 70: 367-378

Kulbicki M, Bozec YM, Labrosse P, Letourneur Y, Mou-Tham G, Wantiez L (2005) Diet composition of carnivorous fishes from coral reef lagoons of New Caledonia. Aquat Living Resour 18:231-250

> Larsen TH, Williams NM, Kremen C (2005) Extinction order and altered community structure rapidly disrupt ecosystem functioning. Ecol Lett 8:538-547

Liddell WD, Ohlhorst SL (1987) Patterns of reef community structure, North Jamaica. Bull Mar Sci 40:311-329

> Loreau M, Naeem S, Inchausti P, Bengtsson J and others (2001) Ecology - Biodiversity and ecosystem functioning: current knowledge and future challenges. Science 294:804-808

Mason NWH, Mouillot D, Lee WG, Wilson JB (2005) Func- 
tional richness, functional evenness and functional divergence: the primary components of functional diversity. Oikos 111:112-118

Mayfield MM, Boni ME, Daily GC, Ackerly D (2005) Species and functional diversity of native and human-dominated plant communities. Ecology 86:2365-2372

McGehee MA (1994) Correspondence between assemblages of coral-reef fishes and gradients of water motion, depth, and substrate size off Puerto Rico. Mar Ecol Prog Ser 105: 243-255

Micheli F, Halpern BS (2005) Low functional redundancy in coastal marine assemblages. Ecol Lett 8:391-400

Munday PL, Jones GP (1998) The ecological implications of small body size among coral-reef fishes. Oceanogr Mar Biol 36:373-411

> Myers RA, Worm B (2003) Rapid worldwide depletion of predatory fish communities. Nature 423:280-283

Naeem S (2002) Disentangling the impacts of diversity on ecosystem functioning in combinatorial experiments. Ecology 83:2925-2935

> Naeem S, Wright JP (2003) Disentangling biodiversity effects on ecosystem functioning: deriving solutions to a seemingly insurmountable problem. Ecol Lett 6:567-579

Naeem S, Thompson LJ, Lawler SP, Lawton JH, Woodfin RM (1994) Declining biodiversity can alter the performance of ecosystems. Nature 368:734-737

Nagelkerken I, van der Velde G, Cocheret de la Morinière E (2001) Fish feeding guilds along a gradient of bay biotopes and coral reef depth zones. Aquat Ecol 35:73-86

Pereira HM, Daily GC, Roughgarden J (2004) A framework for assessing the relative vulnerability of species to landuse change. Ecol Appl 14:730-742

Petchey OL, Gaston KJ (2002a) Extinction and the loss of functional diversity. Proc R Soc Lond B Biol Sci 269:1721-1727

Petchey OL, Gaston KJ (2002b) Functional diversity (FD), species richness and community composition. Ecol Lett 5: 402-411

Petchey OL, Gaston KJ (2006) Functional diversity: back to basics and looking forward. Ecol Lett 9:741-758

Scharf FS, Juanes F, Rountree RA (2000) Predator size-prey size relationships of marine fish predators: interspecific variation and effects of ontogeny and body size on trophicniche breadth. Mar Ecol Prog Ser 208:229-248

Editorial responsibility: Matthias Seaman, Oldendorf/Luhe, Germany
Smith-Vaniz WF, Jelks HL, Rocha LA (2006) Relevance of cryptic fishes in biodiversity assessments: a case study at Buck Island Reef National Monument, St. Croix. Bull Mar Sci 79:17-48

Stevens RD, Cox SB, Strauss RE, Willig MR (2003) Patterns of functional diversity across an extensive environmental gradient: vertebrate consumers, hidden treatments and latitudinal trends. Ecol Lett 6:1099-1108

Taylor MS, Hellberg ME (2005) Marine radiations at small geographic scales: speciation in neotropical reef gobies (Elacatinus). Evolution 59:374-385

Thresher RE, Colin PL (1986) Trophic structure, diversity and abundance of fishes of the deep reef (30-300 m) at Enewetak, Marshall-Islands. Bull Mar Sci 38:253-272

Tilman D, Knops J, Wedin D, Reich P, Ritchie M, Siemann E (1997) The influence of functional diversity and composition on ecosystem processes. Science 277:1300-1302

Vermeij GJ (1996) Marine biological diversity: muricid gastropods as a case study. In: Joablonski D, Erwin DH, Lipps JH (eds) Evolutionary paleobiology. University of Chicago Press, Chicago, IL, p 355-375

Vermeij GJ (2004) Island life: a view from the sea. In: Lomolino MV, Heaney LR (eds) Frontiers in biogeography: new directions in the geography of nature. Sinauer, Sunderland, MA, p 239-254

Veron JEN (1995) Corals in space and time: the biogeography and evolution of the Scleractinia, University of New South Wales Press, Sydney

> Vitt LJ, Pianka ER (2005) Deep history impacts present-day ecology and biodiversity. Proc Natl Acad Sci USA 102: 7877-7881

- Webb CO, Ackerly DD, McPeek MA, Donoghue MJ (2002) Phylogenies and community ecology. Annu Rev Ecol Syst 33:475-505

Westneat MW, Alfaro ME, Wainwright PC, Bellwood DR and others (2005) Local phylogenetic divergence and global evolutionary convergence of skull function in reef fishes of the family Labridae. Proc R Soc Lond B Biol Sci 272: 993-1000

Wright JP, Naeem S, Hector A, Lehman C, Reich PB, Schmid B, Tilman D (2006) Conventional functional classification schemes underestimate the relationship with ecosystem functioning. Ecol Lett 9:111-120

Submitted: July 30, 2007; Accepted: April 24, 2008 Proofs received from author(s): June 27, 2008 